\title{
Voltage-Dependent Switching of Sensorimotor Integration by a Lobster Central Pattern Generator
}

\author{
Romuald Nargeot \\ Universités Bordeaux 1 et 2, Centre National de la Recherche Scientifique, Unité Mixte de Recherche 5543, Laboratoire de Physiologie et Physiopathologie \\ de la Signalisation Cellulaire, 33076 Bordeaux Cedex, France
}

\begin{abstract}
Behavioral adaptations and the underlying neural plasticity may not simply result from peripheral information conveyed by sensory inputs. Central neuronal networks often spontaneously generate neuronal activity patterns that may also contribute to sensorimotor integration and behavioral adaptations. The present study explored a novel form of sensory-induced plasticity by which the resulting changes in motor output depend essentially on the preexisting functional state of an identified neuron of an endogenously active central network. In the isolated lobster stomatogastric nervous system, electrical stimulation of a mechanosensory nerve transiently inactivated rhythmic spike bursting in the lateral pyloric (LP) neuron of the pyloric motor pattern-generating network. Repeated sensory nerve stimulation gradually and long-lastingly strengthened the bursting of the LP neuron to the detriment of sensory-elicited inactivation. This strengthening of pyloric-timed rhythmic activity was enhanced by experimental depolarization of the neuron. Conversely, when the LP neuron was hyperpolarized, the same sensory stimulation paradigm now gradually increased the susceptibility of the pyloric-timed bursting of the network neuron to sensory-elicited inactivation. Modulation of depolarization-activated and hyperpolarization-activated ionic conductances that underlie the intrinsic bursting properties of the LP neuron may contribute via differential voltage-dependent recruitment and effects to the respective adaptive processes. These data therefore suggest a novel state-dependent mechanism by which an endogenously active central network can decrease or increase its responsiveness to the same sensory input.
\end{abstract}

Key words: central pattern generator; sensorimotor adaptation; state-dependent plasticity; modulation; membrane properties; lobster

\section{Introduction}

It is well established that sensory inputs can play a key role in the induction of neuronal plasticity underlying behavioral adaptations. Such inputs can modify motor output depending on their own activity pattern or on the sequence in which different inputs are activated (Antonov et al., 1999, 2001). However, sensorimotor adaptations may not simply result from peripherally originating processes acting on passively responding central neural circuitry. They may also depend on preexisting activity patterns that are endogenously generated by the CNS (Combes et al., 1999; Le Ray and Cattaert, 1999; Nargeot et al., 1999a,b; Spencer et al., 1999; Brembs et al., 2002; Suster and Bate, 2002).

Isolated nervous system preparations have repeatedly demonstrated that rhythmic motor patterns similar to those recorded in behaving animals can be generated independently of sensory inputs as a result of the intrinsic membrane properties and synaptic connectivity of neurons in underlying central networks (Delcomyn, 1980). In adaptive behavioral situations, however, such centrally generated motor patterns are long-lastingly regulated by

Received 0ct. 17, 2002; revised March 26, 2003; accepted March 27, 2003.

Part of this work was performed in the Laboratoire de Neurobiologie des Réseaux, Université Bordeaux 1, Centre National de la Recherche Scientifique, Unité Mixte de Recherche 5816. I thank Drs. H.A. Lechner, R. Miles, and J. Simmers for helpful comments on previous drafts of this manuscript.

Correspondence should be addressed to Dr. Romuald Nargeot, Université Bordeaux 1, Centre National de la Recherche Scientifique, Unité Mixte de Recherche 5816, Laboratoire de Neurobiologie des Réseaux, Bâtiment Biologie Animale-B2, Avenue des Facultés, 33405 Talence Cedex, France. E-mail: r.nargeot@Inr.u-bordeaux.fr. Copyright $\odot 2003$ Society for Neuroscience $\quad$ 0270-6474/03/234803-06\$15.00/0 incoming sensory inputs (Pearson, 2000), although the mechanisms by which central networks integrate new sensory information to alter motor output are still not well understood.

The lobster stomatogastric nervous system (STNS), which controls rhythmic food processing movements of the anterior (cardiac sac) and posterior (pyloric chamber) regions of the foregut, is a suitable preparation to address this problem. The STNS has served as a valuable in vitro preparation for understanding how central neuronal networks [so-called central pattern generators (CPGs)] spontaneously generate motor patterns (Selverston and Moulins, 1987; Nusbaum and Beenhakker, 2002). In addition, an identified multifiber mechanosensory input pathway, the ventral posterolateral nerve (vpln), which is activated by dilation of the cardiac sac, can exert discrete modulatory effects on important aspects of the rhythmic motor pattern generated by the pyloric neural network (Hooper and Moulins, 1990; Hooper et al., 1990; Nargeot, 2001). The present study used the STNS in vitro to investigate the cellular mechanisms by which the vpln long-lastingly adapts pylorictimed activity of an identified network element, the lateral pyloric (LP) neuron. The results suggest that opposite sensory-induced integrative processes are produced depending on preexisting levels of activity in the target neuron itself.

Parts of this paper have been published previously in abstract form (Nargeot, 2002).

\section{Materials and Methods}

Experiments were performed on the isolated STNS of the spiny lobster, Palinurus vulgaris. Dissection and experimental methods were standard 

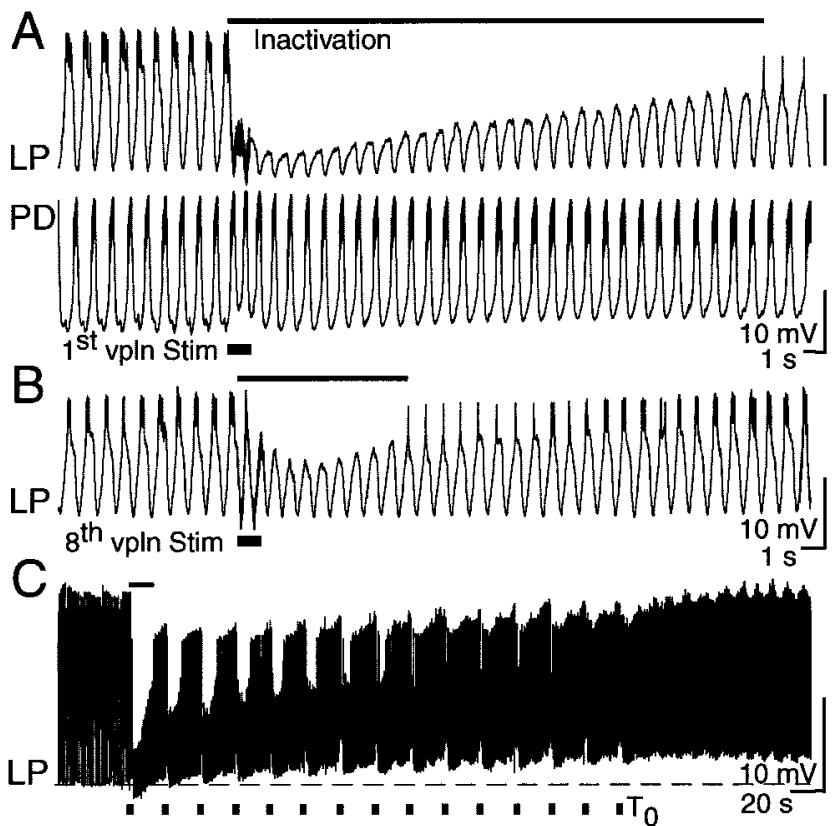
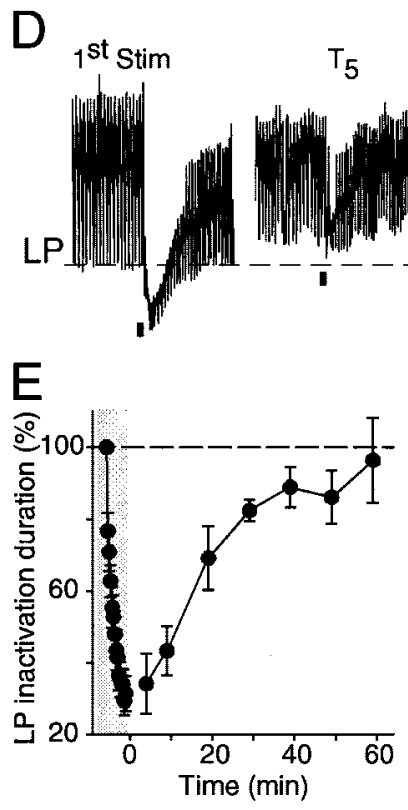

$\mathrm{T}_{5}$

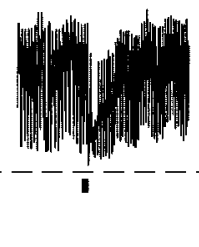

$\mathrm{T}_{20}$

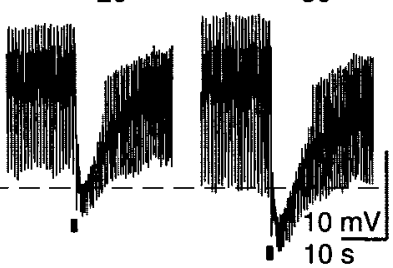

$\mathrm{F}$

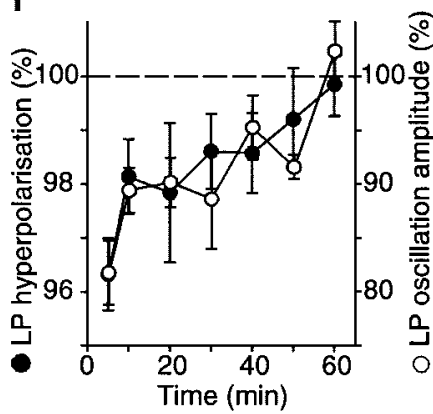

Figure 1. Sensory-induced plasticity of burst inactivation in the pyloric motor pattern-generating network. $A$, Simultaneous recordings of the LP and PD neurons of the pyloric network. A single stimulus train delivered to the vpln selectively inactivated the spontaneous bursting activity of the $L$ P neuron. $B, C$, Repeated (at 20 sec intervals) vpln stimulation ( $B, 8$ th stimulation; $C, 15$ successive stimulations at slower time base) evoked an increasingly rapid recovery of the LP neuron pyloric activity from sensory-elicited inactivation (see also shaded bar in $E$ ). This was associated with a gradual membrane depolarization $(C$, dashed line, $-55 \mathrm{mV}$ ) and a decrease in oscillation amplitude. $D-F$, The changes persisted for $\sim 1 \mathrm{hr}$ after their initial induction. $D$, Left, First of initial series of 15 stimulations as in ( and $E$ (gray box; $p<0.001 ; n=20$ ). From the last stimulation of the induction series (time $0, \mathrm{~T}_{0}$ in $C$ ) until 60 min later $\left(\mathrm{T}_{60}\right.$ ), one to three additional vpln stimulations per preparation were delivered at $\geq 5$ min intervals so as not to permit a decrease in inactivation duration (filled circles in $F, p<0.05$; open circles, $p<0.01 ; n=20$ ).

and similar to those described in detail previously (Nargeot, 2001). Electrophysiology. Extracellular recordings and stimulations were made using wire electrodes placed against nerves and insulated from the bath with petroleum jelly. The protocol for extracellular nerve stimulation of the vpln was $0.5 \mathrm{msec}, 5 \mathrm{~V}$ pulses delivered at $40 \mathrm{~Hz}$ for $1 \mathrm{sec}$. The persistence of any changes in pyloric motor network activity induced by an initial series of 15 such stimulations, delivered at an interval of $20 \mathrm{sec}$ (see Fig. $1 C)$, was tested by one to three additional stimulations $(5 \mathrm{~V}, 40 \mathrm{~Hz}, 1 \mathrm{sec})$ applied at different delays after the initial stimulus series. Intracellular recordings and stimulations were made with glass microelectrodes filled with $3 \mathrm{M} \mathrm{KCl}(10-15 \mathrm{M} \Omega)$.

Input resistance and membrane currents of the LP neuron were recorded by two-electrode current-clamp and voltage-clamp techniques, respectively. In current clamp, current was generated by an Axoclamp-2B amplifier (Axon Instruments, Foster City, CA) driven by a Grass Instruments (Quincy, MA) S88 stimulator. In voltage clamp, chosen membrane potentials were maintained by an Axoclamp-2B driven by pClamp software (Axon Instruments). Scaled leakage and capacitive currents were digitally subtracted before analysis. All currents were filtered by a $1.5 \mathrm{kHz}$ low-pass Bessel filter. For current-clamp and voltage-clamp study, the LP neuron was first isolated in situ from synaptic input from other neurons of the pyloric network. For this, the pyloric dilator (PD) and ventral dilator neurons were photoablated by intracellular injection of 5,6-carboxyfluorescein and illumination with blue light. Synaptic input from remaining glutamatergic pyloric, inferior constrictor, and anterior burster neurons was blocked by superfusion of $10^{-5} \mathrm{M}$ picrotoxin (Miller and Selverston, 1982).

Analysis. The duration of vpln-induced LP neuron inactivation was measured from the beginning of the sensory nerve stimulation until recovery of the first action potential (see Fig. $1 A$ ). Mean values of neuron membrane potential and oscillation amplitude were calculated from samples of five successive bursts (Nargeot, 2001). Amplitude of potential oscillation was measured from the maximum hyperpolarized trough to the value at which the first action potential occurred on the subsequent depolarization. Parts of the data were analyzed offline using Spike2 software (Cambridge Electronic Design, Cambridge, UK). LP neuron input resistance was taken as the mean of five successive measurements in a 1
Hz sampling per preparation and was determined from a holding potential of $-60 \mathrm{mV}$ to the maximum potential deflection elicited by a brief current pulse ( $-2 \mathrm{nA}, 500 \mathrm{msec}$ ). The LP neuron holding potential was set before vpln stimulation by tonic current injection and was not readjusted during experiments. Outward membrane currents were recorded from a holding potential of $-60 \mathrm{mV}$ with a series of $200 \mathrm{msec}$ depolarizing pulses (from -50 to $+40 \mathrm{mV}$, in steps of $10 \mathrm{mV}$ ). The net outward current activated by this paradigm consists mainly of a strong and transient peak of $\mathrm{Ca}^{2+}$-activated $\mathrm{K}^{+}$current, a smaller and persistent delayed-rectifier $\mathrm{K}^{+}$current, and virtually no A-current (HarrisWarrick and Johnson, 1987; Graubard and Hartline, 1991; Golowasch and Marder, 1992; Kiehn and Harris-Warrick, 1992). The net hyperpolarization-activated inward current was recorded from a holding potential of $-50 \mathrm{mV}$ with a series of $5 \mathrm{sec}$ hyperpolarizing pulses (from -60 to $-120 \mathrm{mV}$, in steps of $10 \mathrm{mV}$ ). This protocol activates mainly h-current in oscillatory pyloric neurons (Graubard and Hartline, 1991; Golowasch and Marder, 1992; Kiehn and Harris-Warrick, 1992). Current-voltage $(I-V)$ curves were generated from either the maximum peak of outward current or the mean inward current recorded during the last $500 \mathrm{msec}$ of a voltage pulse. Neurons had an initial input resistance of 4-10 M $\Omega$. Preparations (6\%) in which the spontaneous maximal membrane hyperpolarization of the LP neuron was higher than $-65 \mathrm{mV}$ and/or the neuron was not spontaneously active before vpln stimulation were excluded from analysis. Statistical comparisons of data were made using Student's $t$ test and ANOVA. ANOVA with repeated measures were used in the paired sample procedures. A two-factor ANOVA was used when comparing effects of both repeated vpln stimulation and manipulation of membrane potential in a same LP neuron (see Fig. 3B) (the probability value reported refers to the interaction between the factors). Data are expressed as percentage of initial values and are represented by means \pm SEM.

\section{Results}

The lobster pyloric network continuously generates rhythmic motor output (cycle period, 0.5-2 sec) that results from the spontaneous bursting activity of its constituent neurons (Fig. $1 \mathrm{~A}$, be- 
fore stimulation). The neighboring neural network that generates cardiac sac dilations that activate the sensory vpln is not continuously active and produces a slow motor rhythm with a period of $\sim 10-40 \mathrm{sec}$ (Selverston and Moulins, 1987). To investigate how expression of the cardiac sac rhythm may influence the pyloric network through vpln activation, sensory input was mimicked in the isolated STNS by equivalent cyclic (at 20 sec intervals) vpln electrical stimulations (5 V, $40 \mathrm{~Hz}$ for $1 \mathrm{sec}$ ) (Hooper et al., 1990).

A single shock stimulation of the vpln inactivated bursting in specific pyloric network neurons, including the LP neuron, for several tens of seconds (Fig. 1A, compare simultaneously recorded LP and PD neuron traces). Moreover, as seen in Figure $1 A-C$, repeated sensory nerve stimulation (at $20 \mathrm{sec}$ intervals) elicited successive episodes of LP neuron burst inactivation whose duration decreased progressively, eventually leading to a return to virtually uninterrupted LP neuron pyloric activity. This modification in sensorimotor responsiveness depended on the interval between successive vpln stimulations and was not induced at interstimulus intervals $\geq 5 \mathrm{~min}$. Thus, when applied at such long intervals after an initial inductive series of vpln stimulation, additional single stimuli could be used to test the persistence of the original sensory-induced modification. This sensorimotor plasticity persisted for $\sim 1 \mathrm{hr}$ (Fig. $1 D, E$ ). Moreover, during the sensory-evoked induction of the plasticity (Fig. 1C), the maximal hyperpolarized level and amplitude of the spontaneous membrane potential oscillations of the LP neuron decreased significantly from $-57.4 \pm 0.8$ to $-55.5 \pm 0.9 \mathrm{mV}$ and from $13.3 \pm 0.5$ to $10.8 \pm 0.6 \mathrm{mV}$, respectively $(n=20)$. Recovery to initial control values of the membrane potential of the LP neuron also occurred slowly over the ensuing $1 \mathrm{hr}$ (Fig. 1D,F). Finally, these long-lasting modifications in activity and membrane potential were specific to the LP neuron because no equivalent change occurred in another pyloric circuit neuron, the PD.

To evaluate a possible contribution of changes in the endogenous membrane properties of the LP neuron, the latter was experimentally isolated in situ from the rest of the pyloric network (see Materials and Methods) before applying the vpln stimulation. Significantly, under such conditions, a similar gradual decline in hyperpolarization and oscillation amplitude was observed in synaptically isolated LP neurons $(n=5)$ after repeated vpln stimulation (Fig. $2 A$ ), thereby also strongly suggesting that the adaptation involved a direct action on the intrinsic oscillatory capacity of the target LP neuron itself. Consistent with this conclusion, current- and voltage-clamp investigation of networkisolated LP neurons revealed a long-lasting $(\sim 1 \mathrm{hr})$ and reversible increase in cell input resistance (Fig. $2 B$ ). This was associated with a significant decrease in depolarization-activated ionic currents that probably consisted mainly of $\mathrm{Ca}^{2+}$-activated $\mathrm{K}^{+}$current (Fig. $2 C$, right) and a hyperpolarization-activated current that resembled $I_{\mathrm{h}}$ (Fig. 2D, right) (Golowasch and Marder, 1992; Kiehn and Harris-Warrick, 1992). The $I-V$ relationships of these diminished currents, which included an outward current that activated at potentials above $-50 \mathrm{mV}$ (Fig. $2 \mathrm{C}$ ) and an inward current that activated below $-60 \mathrm{mV}$ (Fig. $2 D$ ), indicated that the change in LP neuron properties could be expressed over a relatively broad range of membrane potential and involved the activation of different membrane channels with opposite ion fluxes.

To further assess the contribution of this voltage dependence to the changes in sensorimotor responsiveness, the duration of vpln-induced inactivation was compared in the same preparations $(n=5)$ at different levels of LP neuron membrane potential during successive (interval of $1 \mathrm{hr}$ ) and identical series of vpln
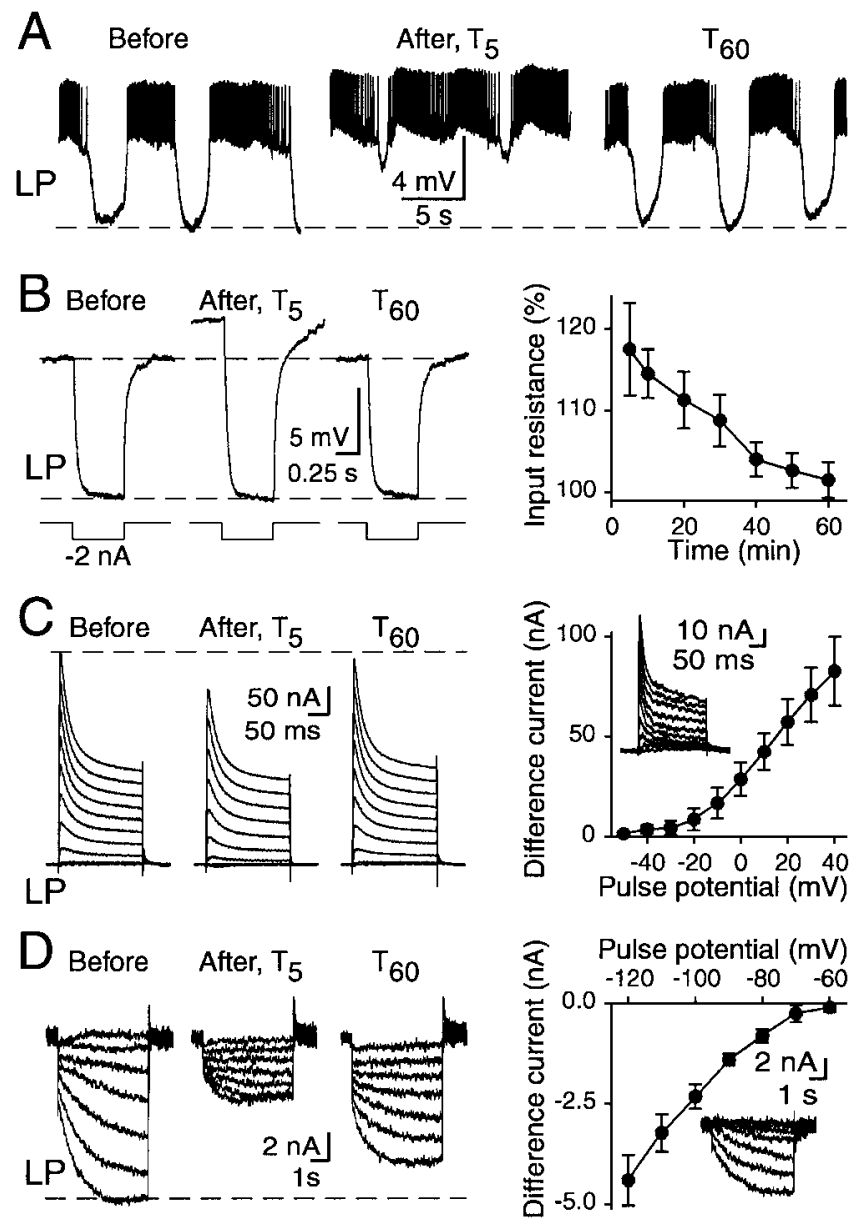

Figure 2. Voltage-dependent changes in membrane properties of network-isolated LP neurons. $A$, Comparison of the intrinsic oscillatory capability of the cells before and at 5 and $60 \mathrm{~min}$ after repeated vpln stimulation (dashed line, $-45 \mathrm{mV}$ ). $B$, Current clamp. An increase in input resistance (measured with $-2 \mathrm{nA}$ injected pulses) occurred after repeated vpln stimulation (dashed lines indicate initial control potential deflection; top line, $-60 \mathrm{mV})(p<0.05 ; n=5)$ and then returned to control over the ensuing $60 \mathrm{~min}$. C, D, Voltage clamp. Depolarizationactivated outward $(C$, left) and hyperpolarization-activated inward $(D$, left) currents were reversibly decreased after the vpln-induced plasticity (dashed line, maximum initial current). $\ln C$ and $D$, right are current-voltage relationships of the outward $(C)$ and inward $(D)$ currents that were modulated by the vpln stimulation. These difference currents (insets) were obtained by subtracting the current recorded 5 min after vpln stimulation $\left(T_{5}\right)$ from the corresponding currents recorded before the sensory-induced plasticity $(n=5)$.

stimulation (Fig. 3). Intrasomatic injection of continuous depolarizing current $(+1 \mathrm{nA})$, which raised the most hyperpolarized potential of the neuron by $\sim 10 \mathrm{mV}$ (to approximately $-50 \mathrm{mV}$ ) above its control value $(-60 \mathrm{mV})$, accelerated the decline in sensory-induced burst inactivation of the LP neuron (Fig. 3A, top, $B$; compare with Fig. $1 C)(p<0.001$ between groups). In contrast, a weak tonic hyperpolarization (with $-0.5 \mathrm{nA}$ ) to $\sim 5$ $\mathrm{mV}$ below the control maximal hyperpolarized level prevented any sensory-evoked alteration of LP neuron inactivation duration (Fig. $3 A$ middle, $B$ ), thereby excluding the possibility of fatigue of the stimulated sensory fibers and/or depression of inactivating influences that are presynaptic to the LP neuron. Most interestingly, however, a stronger tonic hyperpolarization (with $-1 \mathrm{nA}$ ) completely inverted the adaptive process. The inactivation duration now increased during successive sensory nerve stimulations and led progressively to a complete suppression of LP neuron spike burst activity (Fig. 3A, bottom, $B$ ) (no observable change in activity and membrane potential was evident dur- 

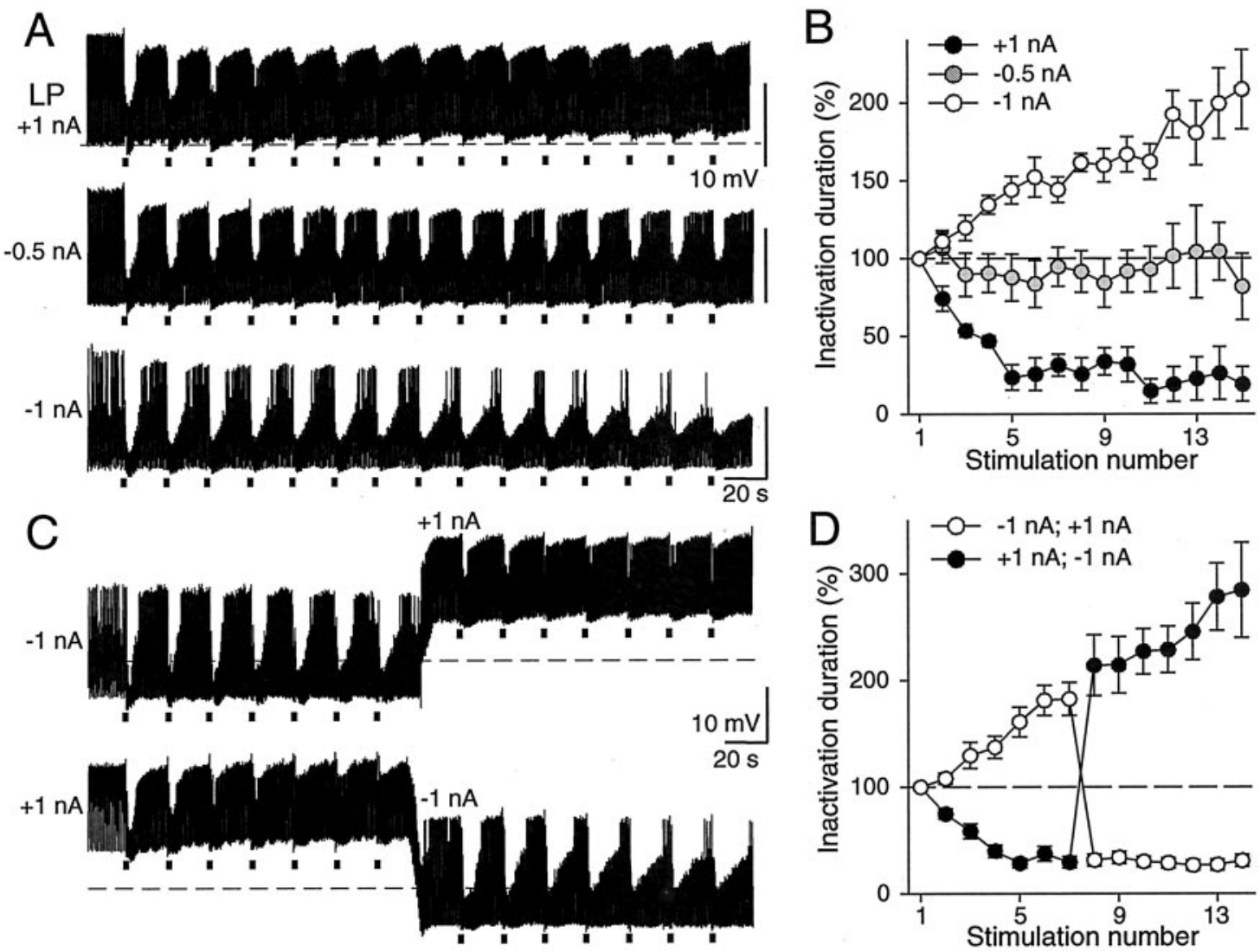

Figure 3. State-dependent switching of sensorimotor integration. $A$, Recording of the same LP neuron (maximal spontaneous membrane hyperpolarization, $-60 \mathrm{mV}$ ) during three identical series of vpln stimulations applied $1 \mathrm{hr}$ apart during intrasomatic injection of different levels of constant current $(+1,-0.5,-1 \mathrm{nA})$. Decrease of the vpln-elicited inactivation recorded during depolarization (top) was suppressed by slightly hyperpolarizing the neuron (middle) and was then switched to a progressive increase in LP neuron sensitivity to sensory-elicited inactivation in a more hyperpolarized neuron (bottom). B, Quantification of normalized inactivation duration in the three situations shown in $A(p<0.001 ; n=5$ ). C, Similar opposing effects were evoked by a sudden change in LP neuron membrane potential (from hyperpolarized to depolarized levels, top; and from depolarized to hyperpolarized levels, bottom) during a single series of vpln stimulation in the same preparation (dashed lines, maximal spontaneous membrane hyperpolarization, $-58 \mathrm{mV}$ ). D, Quantification of changes in inactivation duration seen in C (top in C corresponds to open circles; bottom in ( corresponds to filled circles; $n=4)$.

ing similar current injections but in the absence of vpln stimulation.) Furthermore, an equivalent and immediate switch in sign of the sensorimotor plasticity occurred within a single stimulus series by inverting the polarity of tonically injected current to cause a sudden experimental shift in the membrane potential of the LP neuron (Fig. 3C,D). Thus, the motor adaptation resulted from changes in the voltage-dependent membrane properties of the target pyloric LP neuron rather than from any modification in the presynaptic sensory influence.

Intrinsic activity-dependent regulation of membrane properties (Turrigiano et al., 1994; Marder et al., 1996; Desai et al., 1999) did not appear to contribute to this switching in neuronal plasticity because the injection of hyperpolarizing current pulses $(-4$ $\mathrm{nA}$ for $10 \mathrm{sec}$ at $20 \mathrm{sec}$ interval) to evoke repetitive LP neuron burst inactivation did not alter the duration of a subsequent ( 5 min) vpln-elicited inactivation $(7.5 \pm 1.8 \mathrm{sec})$ compared with that seen before current injection $(6.4 \pm 1.4 \mathrm{sec}$; paired Student's $t$ test; $\left.t_{(4)}=-1.849\right)(n=5$; data not shown). Rather, it is more likely that the extrinsic sensory input directly caused the changes at potentials more than $-65 \mathrm{mV}$ by gradually and persistently suppressing outward membrane current (Fig. 2C), thereby decreasing the intrinsic ability of the LP neuron to repolarize and cease firing in each cycle (Fig. $2 \mathrm{~A}$ ). In contrast, at LP membrane potential levels less than $-65 \mathrm{mV}$, the modulatory repression of an hyperpolarization-activated inward current (Fig. 2D) is con- sistent with a weakened LP neuron oscillatory capability and an associated inability to express bursting activity.

\section{Discussion}

Contribution of preexisting central activity patterns to sensorimotor adaptations

An essential finding in the present study is that a single paradigm of repeated sensory vpln stimulation can either gradually strengthen or suppress the spontaneous activity pattern of a single neuron (LP) in the pyloric central pattern generator, depending on the initial functional state of the target neuron. Thus, the ongoing activity of the pyloric CPG itself, which may vary according to different behavioral states of the animal (Turrigiano and Selverston, 1990; Clemens et al., 1998), plays an essential role in the computational operations that induce and determine the nature of sensory-evoked changes in network output.

The capacity of repeated stimulation of a sensory pathway to gradually and persistently modify a central nervous or behavioral response has been illustrated in different preparations. Such a stimulus paradigm can render sensory inputs ineffective in eliciting a motor response, thereby depressing sensorimotor pathway function (Thompson and Glanzman, 1976; Stopfer et al., 1996; Antonov et al., 1999). Other studies have revealed that similar stimulation paradigms may gradually facilitate neuronal or behavioral responses to a specific sensory influence (Baranaus- 
kas and Nistri, 1998; Herrero et al., 2000), with changes in presynaptic and/or postsynaptic properties contributing to such facilitation. Unlike these cases, however, the plasticity in vpln-LP pathway function does not derive solely from passive responses to a repeated sensory stimulus. Rather, it also implicates the ongoing operation of the central network to which the LP neuron belongs. Activity of the LP neuron either strengthens itself through the integration of new and repeated sensory input or, conversely, adjusts itself to the demands of the input, despite an unchanged stimulus regimen and efficacy of sensory nerve activation. On this basis, therefore, plasticity in the vpln-LP pathway is distinct from previously described forms of sensorimotor adaptations, providing a state-dependent postsynaptic mechanism by which an endogenously active central network is able to upregulate or downregulate its functional susceptibility to the restructuring influences of an extrinsic sensory input. This may in turn provide a flexible neuronal substrate through which, depending on the behavioral state of the animal, the STNS controlling foregut movements may either ensure independent pyloric and anterior cardiac sac activity or, conversely, allow sensory feedback from cardiac sac movement to adjust the pyloric activity for efficient food transfer.

\section{Voltage-dependent plasticity of regenerative membrane properties}

The results of this study demonstrate that the sensorimotor plasticity induced by presynaptic vpln stimulation was at least partly related to long-lasting changes in voltage-dependent properties of the postsynaptic LP neuron. In a depolarized cell, sensoryderived modulation promoted intrinsic LP neuron regenerative membrane properties at the expense of their transient inactivation. Conversely, when the same LP neuron was hyperpolarized, the sensory input weakened the regenerative properties of the neuron, thereby rendering pyloric motor activity more susceptible to sensory-elicited inactivation. As such, according to its membrane potential, the LP neuron can respond to the same sensory input by either a persistent strengthening or weakening of its intrinsic burst-generating properties.

The regenerative membrane properties of central bursting neurons are determined by multiple voltage-dependent membrane conductances that can be modulated by presynaptic inputs (Kiehn and Harris-Warrick, 1992). Additional study will be required to identify and characterize precisely the full spectrum of LP neuron conductances that are modulated by vpln stimulation. Nevertheless, the present study has defined at least two types of conductances that are involved. These conductances are activated in different ranges of membrane potential and convey opposite ion fluxes (presumably inward h-currents and outward $\mathrm{K}_{\mathrm{Ca}^{-}}$ currents). They also have opposite roles in the bursting capabilities of neurons by triggering and terminating spike bursts, respectively (Graubard and Hartline, 1991; Kiehn and Harris-Warrick, 1992). Thus, as suggested by previous theoretical studies (Canavier et al., 1993, 1994; Goldman et al., 2001), the present biological data demonstrate that, according to their specific voltage-dependent recruitment and properties, sensory-elicited modulation of multiple conductances can differentially affect the robustness of bursting properties of a target neuron and, consequently, its responsiveness to extrinsic synaptic inputs.

These results therefore confirm that regenerative properties of bursting neurons can be a substrate for sensory-induced plasticity in neural networks (Marder et al., 1996; Baranauskas and Nistri, 1998; Morisset and Nagy, 1999; Nargeot et al., 1999a,b; Spencer et al., 1999; Woolf and Michael, 2000; Brembs et al.,
2002). Importantly, moreover, they now indicate that such plasticity can be regulated in a voltage-dependent manner to provide different, and even opposing, adaptive responses in the same sensorimotor pathway.

\section{References}

Antonov I, Kandel ER, Hawkins RD (1999) The contribution of facilitation of monosynaptic PSPs to dishabituation and sensitization of the Aplysia siphon withdrawal reflex. J Neurosci 19:10438-10450.

Antonov I, Antonova I, Kandel ER, Hawkins RD (2001) The contribution of activity-dependent synaptic plasticity to classical conditioning in Aplysia. J Neurosci 21:6413-6422.

Baranauskas G, Nistri A (1998) Sensitization of pain pathways in the spinal cord: cellular mechanisms. Prog Neurobiol 54:349-365.

Brembs B, Lorenzetti FD, Reyes FD, Baxter DA, Byrne JH (2002) Operant reward learning in Aplysia: neuronal correlates and mechanisms. Science 296:1706-1709.

Canavier CC, Baxter DA, Clark JW, Byrne JH (1993) Nonlinear dynamics in a model neuron provide a novel mechanism for transient synaptic inputs to produce long-term alterations of postsynaptic activity. J Neurophysiol 69:2252-2257.

Canavier CC, Baxter DA, Clark JW, Byrne JH (1994) Multiple modes of activity in a model neuron suggest a novel mechanism for the effects of neuromodulators. J Neurophysiol 72:872-882.

Clemens S, Combes D, Meyrand P, Simmers J (1998) Long-term expression of two interacting motor pattern-generating networks in the stomatogastric system of freely behaving lobster. J Neurophysiol 79:1396-1408.

Combes D, Meyrand P, Simmers J (1999) Dynamic restructuring of a rhythmic motor program by a single mechanoreceptor neuron in lobster. J Neurosci 19:3620-3628.

Delcomyn F (1980) Neuronal basis of rhythmic behavior in animals. Science 210:492-498.

Desai NS, Rutherford LC, Turrigiano GG (1999) Plasticity in the intrinsic excitability of cortical pyramidal neurons. Nat Neurosci 2:515-520.

Goldman MS, Golowasch J, Marder E, Abbott LF (2001) Global structure, robustness, and modulation of neuronal models. J Neurosci 21:5229-5238.

Golowasch J, Marder E (1992) Ionic currents of the lateral pyloric neuron of the stomatogastric ganglion of crab. J Neurophysiol 67:318-331.

Graubard K, Hartline DK (1991) Voltage clamp analysis of intact stomatogastric neurons. Brain Res 557:241-254.

Harris-Warrick RM, Johnson BR (1987) Potassium channel blockade induces rhythmic activity in a conditional burster neuron. Brain Res 416:381-386.

Herrero JF, Laird JMA, Lopez-Garcia JA (2000) Wind-up of spinal cord neurones and pain sensation: much ado about something? Prog Neurobiol 61:169-203.

Hooper SL, Moulins M (1990) Cellular and synaptic mechanisms responsible for a long-lasting restructuring of the lobster pyloric network. J Neurophysiol 64:1574-1588.

Hooper SL, Moulins M, Nonnotte L (1990) Sensory input induces longlasting changes in the output of the lobster pyloric network. J Neurophysiol 64:1555-1573.

Kiehn O, Harris-Warrick RM (1992) 5-HT modulation of hyperpolarization-activated inward current and calcium-dependent outward current in a crustacean motor neuron. J Neurophysiol 68:496-508.

Le Ray D, Cattaert D (1999) Active motor neurons potentiate their own sensory inputs via glutamate-induced long-term potentiation. J Neurosci 19:1473-1483.

Marder E, Abbott LF, Turrigiano GG, Liu Z, Golowasch J (1996) Memory from the dynamics of intrinsic membrane currents. Proc Natl Acad Sci USA 93:13481-13486.

Miller JP, Selverston AI (1982) Mechanisms underlying pattern generation in lobster stomatogastric ganglion as determined by selective inactivation of identified neurons. II. Oscillatory properties of pyloric neurons. J Neurophysiol 48:1378-1391.

Morisset V, Nagy F (1999) Ionic basis for plateau potentials in deep dorsal horn neurons of the rat spinal cord. J Neurosci 19:7309-7316.

Nargeot R (2001) Long-lasting reconfiguration of two interacting networks by a cooperation of presynaptic and postsynaptic plasticity. J Neurosci 21:3282-3294. 
Nargeot R (2002) A neural analogue of sensory-motor assimilation and accommodation in the lobster stomatogastric nervous system. Soc Neurosci Abstr 28:67.24

Nargeot R, Baxter DA, Byrne JH (1999a) In vitro analog of operant conditioning in Aplysia. I. Contingent reinforcement modifies the functional dynamics of an identified neuron. J Neurosci 19:2247-2260.

Nargeot R, Baxter DA, Byrne JH (1999b) In vitro analog of operant conditioning in Aplysia. II. Modifications of the functional dynamics of an identified neuron contribute to motor pattern selection. J Neurosci 19:2261-2272.

Nusbaum MP, Beenhakker MP (2002) A small-system approach to motor pattern generation. Nature 417:343-350.

Pearson KG (2000) Neural adaptation in the generation of rhythmic behavior. Annu Rev Physiol 62:723-753.

Selverston AI, Moulins M (1987) The crustacean stomatogastric system: a model for the study of central nervous systems (Selverston AI, Moulins M, eds). Heidelberg: Springer.

Spencer GE, Syed NI, Lukowiak K (1999) Neural changes after operant con- ditioning of the aerial respiratory behavior in Lymnaea stagnalis. J Neurosci 19:1836-1843.

Stopfer M, Chen X, Tai YT, Huang GS, Carew TJ (1996) Site specificity of short-term and long-term habituation in the tail-elicited siphon withdrawal reflex of Aplysia. J Neurosci 16:4923-4932.

Suster ML, Bate M (2002) Embryonic assembly of a central pattern generator without sensory input. Nature 416:174-178.

Thompson RF, Glanzman DL (1976) Neural and behavioral mechanisms of habituation and sensitization. In: Habituation: perspectives on child development, animal behavior and neurophysiology (Tighe TJ, Leaton RN, eds), pp 49-93. New York: Wiley.

Turrigiano GG, Selverston AI (1990) A cholecystokinin-like hormone activates a feeding-related neural circuit in lobster. Nature 344:866-868.

Turrigiano G, Abbott LF, Marder E (1994) Activity-dependent changes in the intrinsic properties of cultured neurons. Science 264:974-977.

Woolf CJ, Michael MW (2000) Neuronal plasticity: increasing the gain in pain. Science 288:1765-1768. 